\title{
Measurement of Heat Transfer Coefficients in an Agitated Vessel with Tube Baffles
}

\author{
M. Dostál, K. Petera, F. Rieger
}

\begin{abstract}
Cooling or heating an agitated liquid is a very common operation in many industrial processes. A classic approach is to transfer the necessary heat through the vessel jacket. Another option, frequently used in the chemical and biochemical industries is to use the heat transfer area of vertical tube baffles. In large equipment, e.g. fermentor, the jacket surface is often not sufficient for large heat transfer requirements and tube baffles can help in such cases. It is then important to know the values of the heat transfer coefficients between the baffles and the agitated liquid. This paper presents the results of heat transfer measurements using the transient method when the agitated liquid is periodically heated and cooled by hot and cold water running through tube baffles. Solving the unsteady enthalpy balance, it is possible to determine the heat transfer coefficient. Our results are summarized by the Nusselt number correlations, which describe the dependency on the Reynolds number, and they are compared with other measurements obtained by a steady-state method.
\end{abstract}

Keywords: heat transfer coefficients, agitated vessels, tube baffles.

\section{Introduction}

Cooling or heating agitated liquid in vessels is a basic technological operation in the chemical, biochemical, pharmaceutical, food and processing industries. The cooling or heating rate depends on how the heat is supplied or removed, the mixing intensity and many other parameters. Good knowledge of all parameters is important for the design of real equipment, e.g. fermentors for transforming biomass to biogas.

A very frequent technique for heating or cooling agitated liquids is to transfer heat via the vessel jacket. In the case of large vessels, the heat transfer area of the jacket may not be sufficient, because the relative size of the transfer area decreases with increasing volume (the area increases with power 2 of the characteristic dimension, e.g. diameter, but the volume increases with power 3), or the jacket cannot be used for other, e.g. structural, reasons. In such cases, helical pipe coils or tube baffles can be used, usually with water or steam flowing inside as the heat transfer medium. In addition to the heat transfer, tube baffles also prevent circular motion of the agitated liquid and generate some axial mixing. The areas around the tube baffles are highly turbulent, so good heat transfer rates (coefficients) can be achieved.

The heat transfer rate between tube baffle and an agitated liquid depends on many parameters, e.g. the geometry, the agitated liquid properties, and the mixing intensity, which is influenced by the type of agitator and its rotation rate. The influence of most of these parameters can be represented by heat transfer coefficient $\alpha$. Heat transfer rate $\dot{Q}$ between the agitated liquid and the tube baffle can then be expressed as

$$
\dot{Q}=\alpha S \Delta \bar{T}
$$

where $S$ is the heat transfer area of the tube baffle, and $\Delta \bar{T}$ represents the characteristic mean temperature difference. This paper uses the transient method to find heat transfer coefficient $\alpha$ on tube baffles in a vessel mixed by a six-blade turbine impeller with pitched blades.

Dimensionless parameters are usually used to describe the relation between heat transfer coefficients and other parameters, e.g. mixing intensity. The resulting dimensionless correlations based on data from small laboratory equipment can be then used to predict the rate of heat transfer in large-scale plant vessels. Basic dimensionless parameters are the Reynolds number

$$
\operatorname{Re}=\frac{N d^{2} \varrho}{\mu}
$$

the Prandtl number

$$
\operatorname{Pr}=\frac{\nu}{a}=\frac{\mu c_{\mathrm{P}}}{\lambda} .
$$

and the Nusselt number, which includes the heat transfer coefficient $\alpha$

$$
\mathrm{Nu}=\frac{\alpha D}{\lambda} .
$$

Here, $D$ is the vessel diameter and $\lambda$ is the thermal conductivity of the agitated liquid. A general relation between all these dimensionless numbers is usually written as

$$
\mathrm{Nu}=f(\operatorname{Re}, \mathrm{Pr}, \text { geometry) },
$$

and the following form is often seen in the literature

$$
\mathrm{Nu}=c \operatorname{Re}^{m} \operatorname{Pr}^{n} \mathrm{Vi}^{s} .
$$

The last term on the right-hand side is Sieder-Tate's correction factor, which represents the change in the 
thermophysical properties of an agitated liquid near the heat transfer wall (tube baffle, in our case). Reynolds power $m$ is usually within the range $2 / 3$ ...3/4. Prandtl power $n$ is commonly given as $1 / 3$, and Sieder-Tate's correction term power $s$ is 0.14 . Viscosity number $\mathrm{Vi}$ is defined as the ratio of the agitated liquid dynamic viscosity at mean temperature and heat transfer wall temperature.

$$
\mathrm{Vi}=\frac{\bar{\mu}}{\mu_{\mathrm{w}}}
$$

Many correlations for the Nusselt number describing the heat transfer in jacketed vessels agitated by six-blade turbines with pitched angle $45^{\circ}$ can be found in the literature. For example, Chisholm [1] reported

$$
\mathrm{Nu}=0.52 \operatorname{Re}^{2 / 3} \operatorname{Pr}^{1 / 3} \mathrm{Vi}^{0.14}
$$

and Rieger et al. [2] used

$$
\mathrm{Nu}=0.56 \operatorname{Re}^{0.67} \operatorname{Pr}^{1 / 3} \mathrm{Vi}^{0.14} \text {. }
$$

Karcz and Stręk [3] presented the results of heat transfer coefficient measurements for various threeblade propellers and various configurations of tube baffles. The following correlation is for a three-blade propeller

$$
\mathrm{Nu}=0.494 \operatorname{Re}^{0.67} \operatorname{Pr}^{1 / 3} \mathrm{Vi}^{0.14}
$$

and for HE3 impeller they presented

$$
\mathrm{Nu}=0.513 \operatorname{Re}^{0.67} \operatorname{Pr}^{1 / 3} \mathrm{Vi}^{0.14} .
$$

Karcz et al. [4] measured the heat transfer coefficients for Rushton and Smith turbine impellers, sixblade and three-blade impellers with pitched angle $45^{\circ}$, a three-blade propeller, and six various geometrical configurations of tube baffles. They presented the results using energy characteristics describing the dependency of the Nusselt number on the modified Reynolds number

$$
\operatorname{Re}^{*}=\frac{(P / V) D^{4} \varrho^{2}}{\mu^{3}},
$$

where $P$ is agitator power input and $V$ is volume of the agitated liquid. The general Nusselt correlation (6) then transforms to (liquid height equal to vessel diameter, and flat bottom)

$$
\mathrm{Nu}=K\left(\frac{\pi}{4}\right)^{m / 3} \operatorname{Re}^{* m / 3} \operatorname{Pr}^{n} \operatorname{Vi}^{s} .
$$

Lukeš [5] also measured heat transfer coefficients in a vessel with tube baffles. He compared the results obtained for a two-stage impeller (combining an axial and radial type impeller) to a three-blade turbine with pitched angle $45^{\circ}$. The following correlation describes a pitched three-blade impeller

$$
\mathrm{Nu}=0.5416 \operatorname{Re}^{0.6576} \operatorname{Pr}^{1 / 3} \mathrm{Vi}^{0.14} .
$$

\section{Theoretical basics of the transient method}

The transient method is based on time monitoring the temperature of an agitated liquid. Assuming a perfectly mixed liquid with constant temperature $T$ throughout its entire volume, a perfectly insulated system with no heat sources (e.g. dissipation of the mechanical energy of the impeller), constant liquid mass $M$ and its specific heat capacity $c_{\mathrm{P}}$, we can write the unsteady enthalpy balance

$$
M c_{\mathrm{P}} \frac{\mathrm{d} T}{\mathrm{~d} t}=\dot{Q} .
$$

Heat flow rate $\dot{Q}$ on the right-hand side of Eq. (15) is proportional to the heat transfer coefficient $\alpha$, heat transfer area of the tube baffle $S$, and the characteristic mean temperature difference between the agitated liquid and the tube surface $\Delta \bar{T}$, see Eq. (1). To express this mean temperature difference, we need to know the surface (wall) temperature $T_{w}$. One way is to measure it directly, as we did for the jacket surface in our previous work [6]. The other way is to use the enthalpy balance of cooling or heating water inside the tube baffle, as is usual in heat exchanger design theory, see for example [7]. In this case, we also have to take into account the heat transfer inside the tube and determine the corresponding heat transfer coefficient $\alpha_{\mathrm{i}}$. Assuming constant specific heat capacity of the heat transfer media $c_{\mathrm{PB}}$ and constant values of the heat transfer coefficients on both sides of the tube, we can express the heat flow rate as

$$
\dot{Q}=k S \Delta T_{\ln },
$$

where $k$ is the overall heat transfer coefficient and $\Delta T_{\ln }$ is the logarithmic mean temperature difference between the agitated liquid and the heat transfer media.

$$
\Delta T_{\ln }=\frac{T_{\mathrm{B}}^{\prime}-T_{\mathrm{B}}^{\prime \prime}}{\ln \frac{T_{\mathrm{B}}^{\prime}-T}{T_{\mathrm{B}}^{\prime \prime}-T}}
$$

Neglecting the tube baffle wall thickness in the case of materials with big thermal conductivities (e.g. copper), the overall heat transfer coefficient can be expressed using the heat transfer coefficients on both sides

$$
k=\left(\frac{1}{\alpha}+\frac{1}{\alpha_{\mathrm{i}}}\right)^{-1} .
$$

Heat transfer rate $\dot{Q}$ at a specific time can also be expressed using the enthalpy balance of the heating or cooling media

$$
\dot{Q}=\dot{m}_{\mathrm{B}} c_{\mathrm{PB}}\left(T_{\mathrm{B}}^{\prime}-T_{\mathrm{B}}^{\prime \prime}\right)
$$




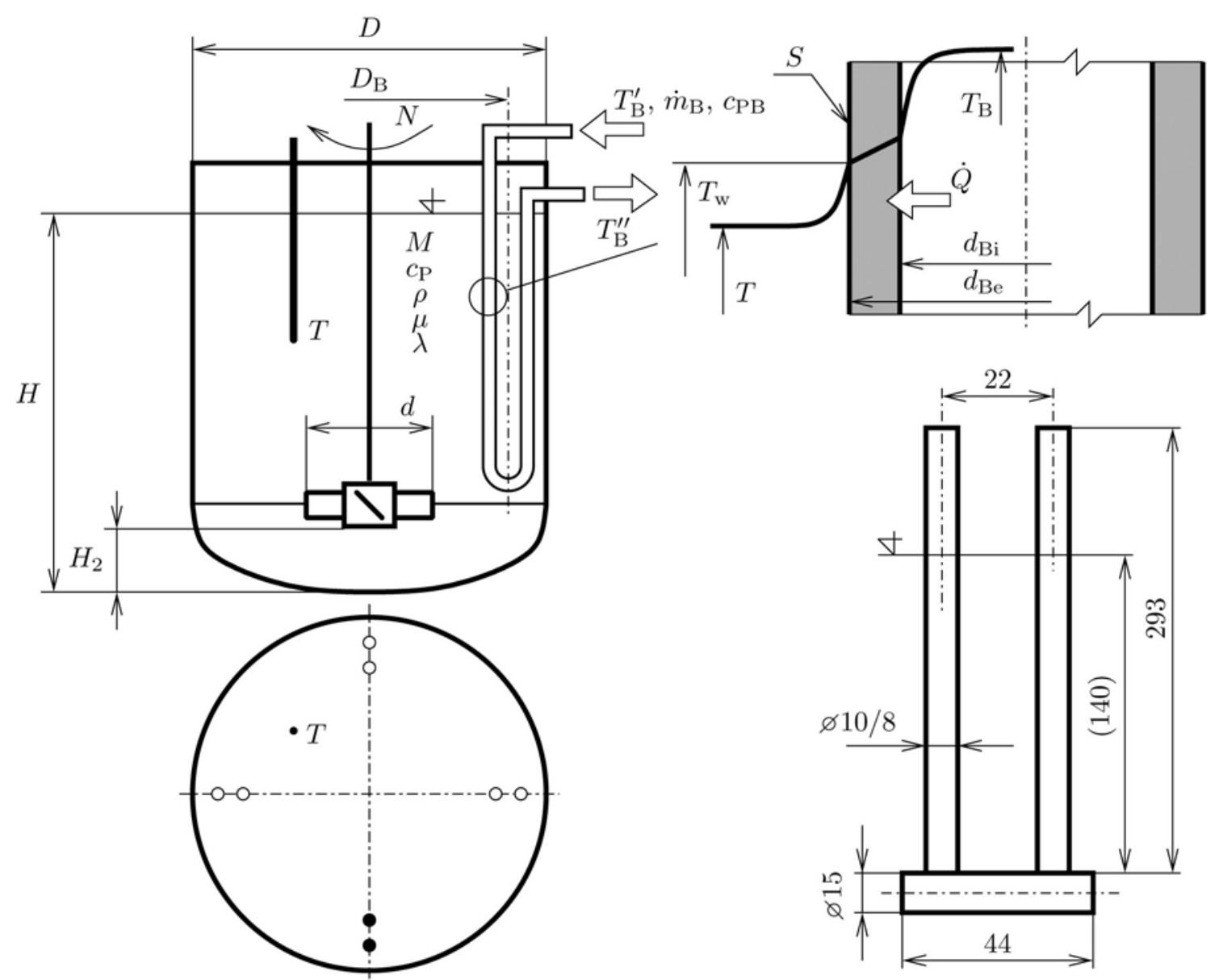

Fig. 1: Schema of our experimental equipment

Substituting (16) and (17) into (15), we get the first order ordinary differential equation

$$
M c_{\mathrm{P}} \frac{\mathrm{d} T}{\mathrm{~d} t}=k S \frac{T_{\mathrm{B}}^{\prime}-T_{\mathrm{B}}^{\prime \prime}}{\ln \frac{T_{\mathrm{B}}^{\prime}-T}{T_{\mathrm{B}}^{\prime \prime}-T}} .
$$

Using the initial condition for agitated liquid temperature

$$
\left.T\right|_{t=0}=T_{0}
$$

we can solve Eq. (20) and get a time course of the temperature of the agitated liquid. In the case of constant inlet temperature $T_{\mathrm{B}}^{\prime}$, we can directly use the enthalpy balance (19) to find the outlet temperature of the cooling/heating media $T_{\mathrm{B}}^{\prime \prime}$, and the ordinary differential equation (20) has an analytical solution. In our transient method, the inlet and outlet temperatures change in time; we measure them together with the temperature of the agitated vessel $T_{i}$ and we have to use some numerical method to solve Eq. (20).

The solution gives us theoretical time profile $T(t)$ for a given overall heat transfer coefficient $k$ and the measured inlet and outlet temperatures of the heat transfer media. The real heat transfer coefficient $k$ should ensure small deviations of the theoretical tem- perature $T(t)$ time profile from the measured profile $T_{i}$. Mathematically, we can look for such a value of $k$ which minimizes the sum of squares of the deviations

$$
\sum_{i=1}^{n}\left(T\left(t_{i}\right)-T_{i}\right)^{2}=\min .
$$

Using this condition, we get an optimal value of the overall heat transfer coefficient $k$ which best fits our experimental data. To express the heat transfer coefficient on the side of agitated liquid $\alpha$ from Eq. (18), we have to know the heat transfer coefficient inside the tube baffle $\alpha_{\mathrm{i}}$. It mostly depends on the geometry and the flow regime. For turbulent flow of a Newtonian liquid in a pipe of circular cross-section, [8] gave the correlation

$$
\begin{aligned}
& \mathrm{Nu}_{\mathrm{B}}=\frac{\alpha_{i} d_{\mathrm{Bi}}}{\lambda_{\mathrm{B}}}= \\
& =\frac{(\xi / 8) \operatorname{Re}_{\mathrm{B}} \operatorname{Pr}_{\mathrm{B}}}{1+12.7 \sqrt{\xi / 8}\left(\operatorname{Pr}_{\mathrm{B}}^{2 / 3}-1\right)}\left[1+\left(\frac{d_{\mathrm{Bi}}}{l_{\mathrm{B}}}\right)^{2 / 3}\right]
\end{aligned}
$$

where $\xi$ is defined

$$
\xi=\left(1.8 \log \operatorname{Re}_{\mathrm{B}}-1.5\right)^{-2}
$$


Table 1: Geometrical parameters of our experimental equipment, and thermophysical properties of the agitated liquid

\begin{tabular}{|c|c|c|c|c|}
\hline Vessel diameter & $D$ & 200 & $\mathrm{~mm}$ & \\
\hline Liquid height & $H$ & 200 & $\mathrm{~mm}$ & $H / D=1$ \\
\hline Inner baffle diameter & $d_{\mathrm{Bi}}$ & 8 & $\mathrm{~mm}$ & \\
\hline Outer baffle diameter & $d_{\mathrm{Be}}$ & 10 & $\mathrm{~mm}$ & $d_{\mathrm{Be}} / D=0.05$ \\
\hline Baffles circle diameter & $D_{\mathrm{B}}$ & 144 & $\mathrm{~mm}$ & $D_{\mathrm{B}} / D=0.72$ \\
\hline Number of baffles & & 4 & & \\
\hline Baffles material & copper & & & \\
\hline Heat transfer area & $S$ & 0.011 & $\mathrm{~m}^{2}$ & \\
\hline Impeller type & six-blad & turbine, pitch & d angle $45^{\circ}$ & \\
\hline Impeller diameter & $d$ & 67 & $\mathrm{~mm}$ & $D / d=3$ \\
\hline Impeller height above bottom & $H_{2}$ & 67 & $\mathrm{~mm}$ & $H_{2} / d=1, H_{2} / D=1 / 3$ \\
\hline Blade width & $b$ & 13 & $\mathrm{~mm}$ & $b / D=0.065, b / d=0.194$ \\
\hline Impeller rotation rate & $N$ & $200-1200$ & $\min ^{-1}$ & \\
\hline Agitated liquid & distilled & water & & \\
\hline Average temperature & $\bar{T}$ & 30 & ${ }^{\circ} \mathrm{C}$ & \\
\hline Density at $\bar{T}$ & $\varrho$ & 995.7 & $\mathrm{~kg} \mathrm{~m}^{-3}$ & \\
\hline Specific heat capacity & $c_{\mathrm{P}}$ & 4178 & $\mathrm{~J} \mathrm{~kg}^{-1} \mathrm{~K}^{-1}$ & \\
\hline Thermal conductivity & $\lambda$ & 0.618 & $\mathrm{~W} \mathrm{~m}^{-1} \mathrm{~K}^{-1}$ & \\
\hline Dynamic viscosity & $\mu$ & $0.7966 \cdot 10^{-3}$ & $\mathrm{Pas}$ & \\
\hline Prandtl number & $\operatorname{Pr}$ & 5.39 & & \\
\hline Thermal diffusivity & $a$ & $0.148 \cdot 10^{-6}$ & $\mathrm{~m}^{2} \mathrm{~s}^{-1}$ & \\
\hline Agitated liquid mass & $M$ & 5.760 & $\mathrm{~kg}$ & \\
\hline
\end{tabular}

and the Reynolds number for a circular pipe with diameter $d_{\mathrm{Bi}}$ is

$$
\operatorname{Re}_{\mathrm{B}}=\frac{\bar{u}_{\mathrm{B}} d_{\mathrm{Bi}} \varrho_{\mathrm{B}}}{\mu_{\mathrm{B}}}
$$

The mean velocity of heating (cooling) transfer media $\bar{u}_{\mathrm{B}}$ can be written as

$$
\bar{u}_{\mathrm{B}}=\frac{4 m_{\mathrm{B}}}{\pi \varrho_{\mathrm{B}} d_{\mathrm{Bi}}^{2}} .
$$

As already mentioned, it is not possible to solve the ordinary differential equation (20) analytically because the inlet and outlet temperatures, $T_{\mathrm{B}}^{\prime}$ and $T_{\mathrm{B}}^{\prime \prime}$, of the heating or cooling liquid flowing inside the tube baffle change with time. In our case, we used the improved Euler method with second order accuracy, see $[9]$

$$
\begin{aligned}
T_{n+1} & =T_{n}+0.5\left(k_{1}+k_{2}\right) \\
k_{1} & =\Delta t f\left(t_{n}, T_{n}\right), \\
k_{2} & =\Delta t f\left(t_{n}+\Delta t, T_{n}+k_{1}\right)
\end{aligned}
$$

which solves an ordinary differential equation with right-hand side $f(t, T)$, corresponding in our case to the right-hand side of Eq. (20) divided by $M c_{\mathrm{P}}$

$$
\frac{\mathrm{d} T}{\mathrm{~d} t}=f(t, T)=\frac{k S}{M c_{\mathrm{P}}} \frac{T_{\mathrm{B}}^{\prime}-T_{\mathrm{B}}^{\prime \prime}}{\ln \frac{T_{\mathrm{B}}^{\prime}-T}{T_{\mathrm{B}}^{\prime \prime}-T}} .
$$

This means that in every step of our optimization procedure described by Eq. (22) it is necessary to numerically solve the previous differential equation. This sets higher demands on computational resources, but they can be satisfied using present-day computers, and the optimization process can be implemented by high-level programming language systems like Matlab ${ }^{\mathbb{R}}$ or Octave.

\section{Experimental}

Measurements of the heat transfer coefficient between the agitated liquid and the tube baffle, using the transient method as described in the previous section, were carried out in a cylindrical vessel with an elliptical bottom $200 \mathrm{~mm}$ in diameter. The vessel was insulated by a polystyrene jacket. Four two-tube baffles were used, regularly positioned by $90^{\circ}$ along the vessel wall. A six-blade turbine impeller with pitched angle $45^{\circ}$ was used. The geometrical and other parameters are depicted in detail in Figure 1 and Table 1. 


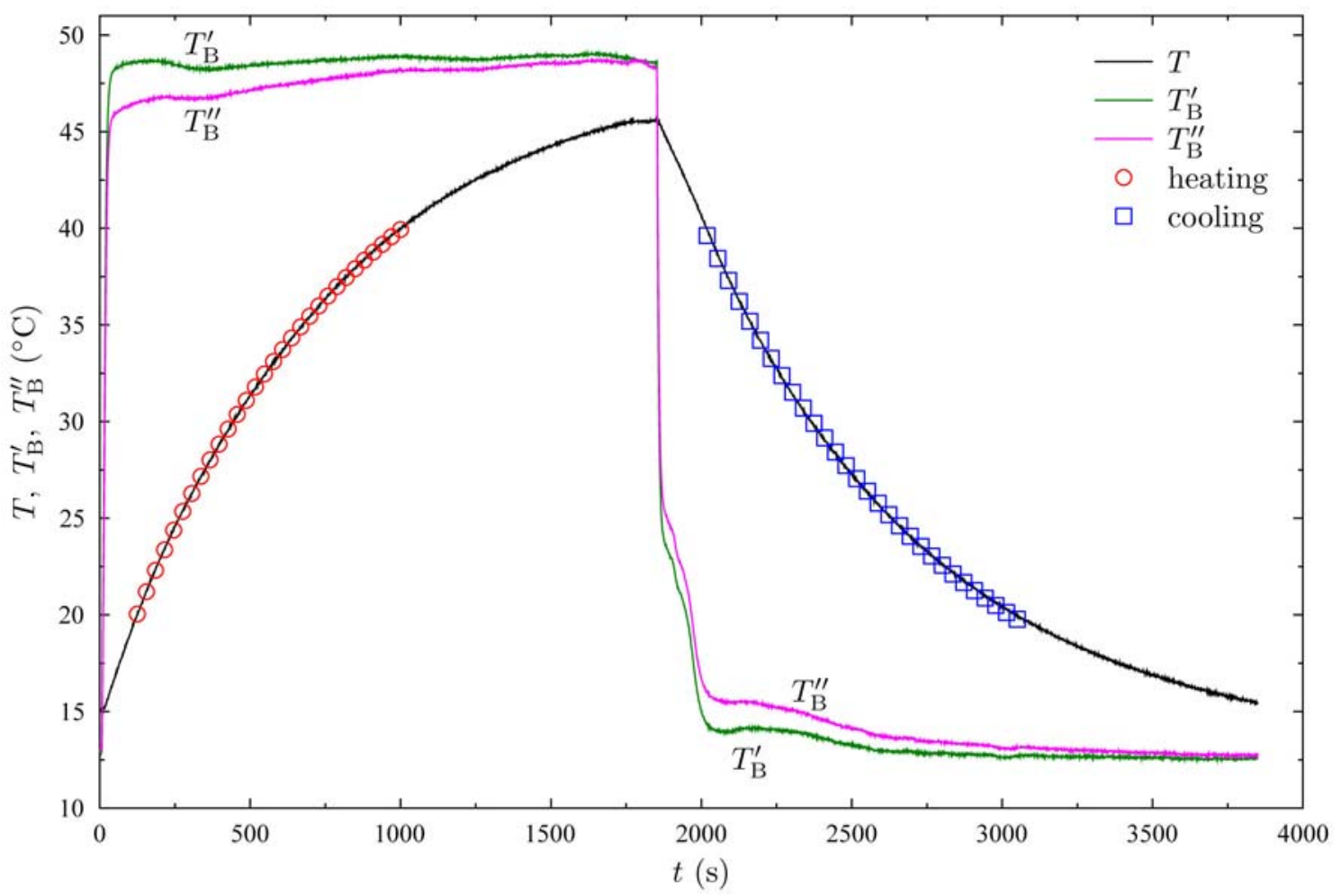

Fig. 2: Typical time courses of the agitated liquid, inlet and outlet temperatures of cooling/heating media flowing in the tube baffle during a single heating/cooling cycle, $N=500 \mathrm{~min}^{-1}$. Red and blue circles outline the results of numerical integration with best-fit values of overall heat transfer coefficients $k$

The agitator was driven by a Servodyne 5000-45 power unit (Cole Parmer Instrument Co., 150-6000 $\mathrm{min}^{-1}$ ). Distilled water was used in the vessel, and its temperature was measured using a Pt100 platinum resistance thermometer, placed in the area between the impeller and the tube baffles, see Fig. 1. Public water mains were used to supply hot or cold water into the tube baffles. The inlet and outlet temperatures of the heat transfer media were again measured using Pt100 platinum resistance thermometers, and the flow rate was determined by weighing the liquid passed in a specific time interval. The platinum resistance thermometers were calibrated before the experiments, using an accurate laboratory mercury thermometer, to obtain the dependency of their resistance on temperature (standard relations for Pt100 were not used).

The resistance of the Pt100 thermometers was measured using the four-wire method and the Agilent 34970A programmable multimeter (Agilent Technologies). The multimeter contains an integration type A/D converter, so we set the integration period to $20 \mathrm{~ms}$, which corresponds to the period length of the voltage supply (frequency $50 \mathrm{~Hz}$ ). The temperatures of the agitated liquid and the heat transfer media were measured with period $1 \mathrm{~s}$.

Measurements were performed periodically. First, the whole equipment was assembled (tube baffles and impeller) and the amount of agitated liquid was weighed. Then, the liquid agitated at constant impeller rotation speed was cooled down to a low temperature by cold water flowing through the baffle. After reaching a steady state, we switched to hot water. The agitated liquid temperature started to increase, and it was measured together with the inlet and outlet temperatures of the water running inside the baffle until the agitated liquid temperature approached the inlet hot water temperature. During this period, samples of flowing water were weighed in order to determine the mass flow rate. Then, we switched to cold water again and repeated the whole measurement process during cooling of the agitated liquid. Figure 2 shows a typical time course of temperatures measured during one experiment cycle for a specific rotation rate.

The heat transfer coefficient was not evaluated using the whole time course. It is obvious from Figure 2 that the measured temperatures of the agitated liquid are within the range of $15^{\circ} \mathrm{C}$ through $45^{\circ} \mathrm{C}$, which corresponds to the water mains temperatures. We used a narrower temperature range $20-40^{\circ} \mathrm{C}$ to evaluate the heat transfer coefficient, as described in the previous section. The mean temperature of this range was $30^{\circ} \mathrm{C}$, which was close to the ambient temperature, it therefore practically prevented substantial heat exchange between the agitated liquid and the surroundings, and minimized the measurement errors (these were neglected in our mathematical model). 
Table 2: Evaluated heat transfer coefficients during heating/cooling cycle for different impeller rotation speeds. In the last column, heat transfer coefficients inside tube baffles were calculated using Eq. (23) and measured flow rate

\begin{tabular}{cccccc}
\hline$N\left(\mathrm{~min}^{-1}\right)$ & $\mathrm{Re}$ & $\alpha\left(\mathrm{W} \mathrm{m}^{-2} \mathrm{~K}^{-1}\right)$ & $\mathrm{Nu}$ & $\mathrm{Vi}^{0.14}$ & $\alpha_{\mathrm{i}}$ \\
\hline 200 & 18681 & $2455 / 2218$ & $794 / 717$ & $1.0410 / 0.9532$ & $16941 / 14052$ \\
300 & 28021 & $3199 / 2900$ & $1034 / 938$ & $1.0420 / 0.9555$ & $17091 / 13128$ \\
400 & 37362 & $3831 / 3486$ & $1239 / 1127$ & $1.0398 / 0.9583$ & $16879 / 13107$ \\
500 & 46702 & $3890 / 4061$ & $1258 / 1313$ & $1.0391 / 0.9630$ & $14796 / 11683$ \\
500 & 46702 & $3798 / 4036$ & $1228 / 1305$ & $1.0404 / 0.9592$ & $16898 / 13205$ \\
600 & 56042 & $4956 / 4519$ & $1602 / 1461$ & $1.0380 / 0.9638$ & $16106 / 11243$ \\
700 & 65383 & $5498 / 5028$ & $1778 / 1626$ & $1.0362 / 0.9633$ & $17275 / 12459$ \\
800 & 74723 & $6039 / 5522$ & $1953 / 1785$ & $1.0371 / 0.9629$ & $17332 / 13729$ \\
900 & 84064 & $6467 / 5950$ & $2091 / 1924$ & $1.0342 / 0.9637$ & $16970 / 13945$ \\
1000 & 93404 & $7006 / 6357$ & $2265 / 2056$ & $1.0344 / 0.9682$ & $17032 / 11487$ \\
1200 & 112085 & $8045 / 7737$ & $2601 / 2502$ & $1.0324 / 0.9545$ & $18595 / 13338$ \\
\hline
\end{tabular}

\section{Measured data evaluation}

The measured data was processed in two steps. In the first step, we determined the heat transfer coefficients for specific rotation rates, and in the second step the Nusselt correlation parameters were determined.

In the first step, we obtained the time courses of the measured temperatures during one heating/cooling cycle for a specific rotation rate, as displayed in Figure 2. Using a numerical solution of Eq. (28) and minimizing the sum of squares (22), we found the overall heat transfer coefficient $k$ which best described the measured temperature profile. The red and blue circles in Figure 2 outline the result of this numerical solution using the best-fit values. See [10] for more details and some Matlab code examples. This procedure was applied to both the heating phase and the cooling phase, so we had two different values of the overall heat transfer coefficients, one for heating, and the other for cooling.

Using Eq. (23) and the measured mass flow rate of the heating (cooling) water, the heat transfer coefficients inside the tube baffles can be calculated, and it is easy to express the heat transfer coefficients on the agitated liquid side from Eq. (18).

$$
\alpha=\left(\frac{1}{k}-\frac{1}{\alpha_{\mathrm{i}}}\right)^{-1}
$$

These values for different rotation speeds are shown in Table 2 which presents the results of the first data evaluation step (pairs of values delimited by a forward slash correspond to heating and cooling, respectively). Other columns in this table show the calculated values of Nusselt numbers, and also the viscosity numbers, which describe the influence of temperature on the thermophysical properties near the heat transfer area (baffles).
The second step of our data evaluation focused on finding optimal values of parameters $c$ and $m$ in Eq. (6) for the Nusselt number. Again, this was based on minimizing the sum of squares of the deviations, defined as

$$
\mathrm{SS}=\sum_{i=1}^{n}\left[c \operatorname{Re}_{i}^{m} \operatorname{Pr}^{1 / 3}-\mathrm{Nu}_{i} / \mathrm{Vi}_{i}^{0.14}\right]^{2}=\min ,
$$

where $\mathrm{Re}_{i}, \mathrm{Nu}_{i}$ and $\mathrm{Vi}_{i}^{0.14}$ correspond to individual rows in Table 2 (the Prandtl number was calculated for the mean temperature of agitated liquid $\bar{T}=30^{\circ} \mathrm{C}$, and the last row with rotation rate $1200 \mathrm{~min}^{-1}$ was skipped in the optimization procedure because one thermometer broke during the experiment and the calculated values of the heat transfer coefficients were therefore inaccurate). The result of this optimization procedure (nonlinear regression, actually) is the following correlation, describing the Nusselt number for our case of heating or cooling of an agitated liquid using tube baffles

$$
\mathrm{Nu}=0.54 \operatorname{Re}^{0.675} \operatorname{Pr}^{1 / 3} \mathrm{Vi}^{0.14}
$$

Figure 3 compares our results with other data in the literature $[5,2,3,1]$.

\section{Confidence interval analysis}

Confidence intervals are omitted in many papers, especially when dealing with a nonlinear regression. However, they are important, as they can show how precisely the parameters were determined. They usually express some $(95 \%)$ probability that a true parameter value lies within certain interval. If this interval is wide, then we do not know the parameter value well and we should probably obtain more (precise) data or 


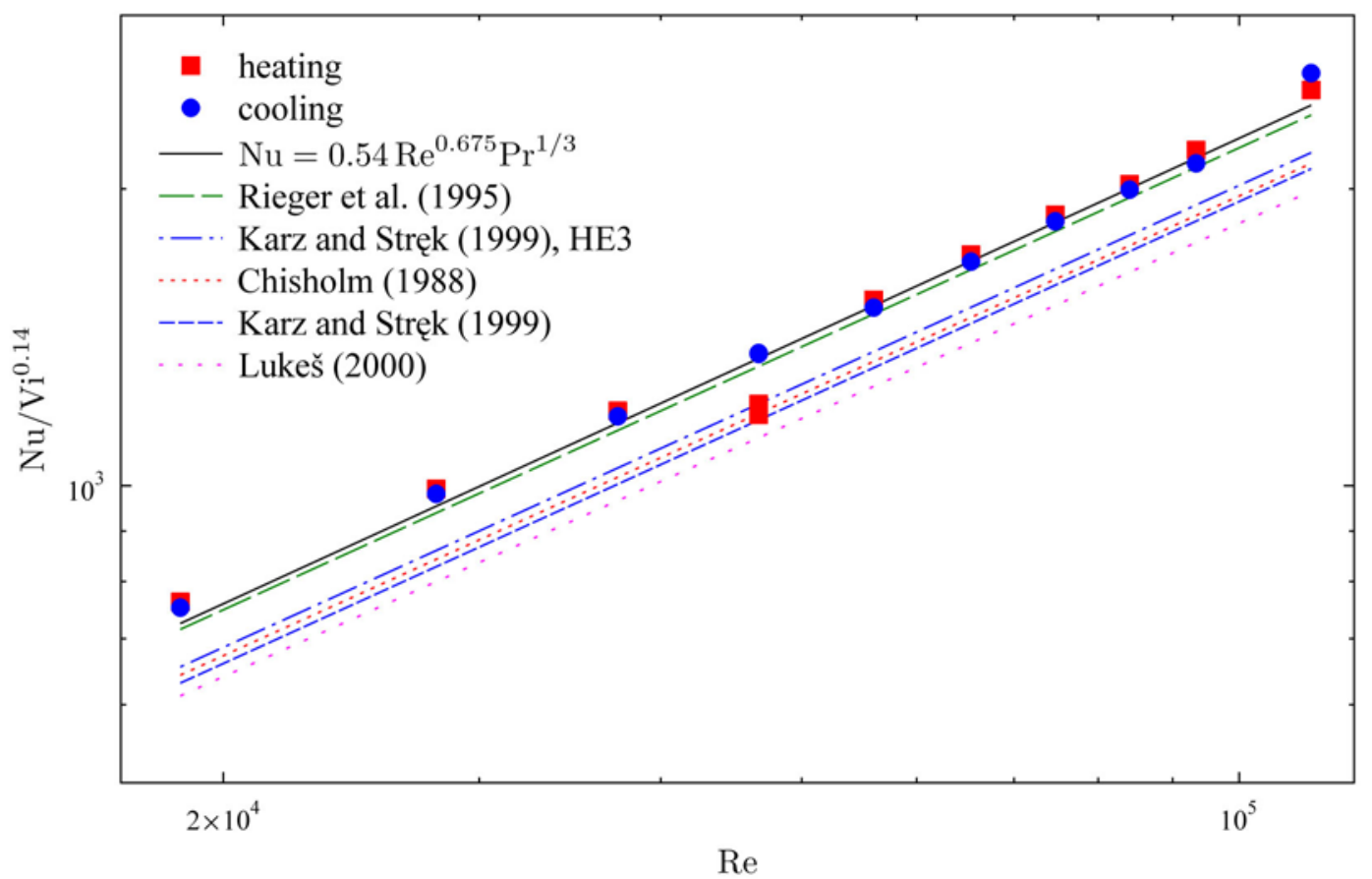

Fig. 3: Our measured data points and the Nusselt correlation described by Eq. (31). Correlations from [5, 2, 3, 1] are depicted for comparison

redefine our model function. This "qualitative" conclusion can be made for the case of nonlinear regression with approximate (asymptotic) intervals. In our case, we have determined them for the two parameters in Eq. (31) using Matlab command nlparci as

$$
\begin{array}{rllll}
c & =0.540 \pm 0.278, & 0.262 & \ldots & 0.818 \\
m & =0.675 \pm 0.047, & 0.628 & \ldots & 0.722
\end{array}
$$

Parameter $m$ has a relatively narrow confidence interval, so we can be satisfied. This is not the case for parameter $c$, which has quite a large confidence interval. What does this show? Well, yes, we have a small data set here and it would be nice to have more data points and more accurate data points. The other reason is that parameter $c$ is closely connected with $m$, and if $m$ is changed only a little, the consequence is a relatively large change in $c$. If we fixed parameter $m$ to some constant value, for example 0.67 , then we would obtain a very narrow confidence interval for $c$

$$
c=0.571 \pm 0.010
$$

which confirms a high correlation of the two parameters. This is also confirmed by the correlation coefficient or matrix

$$
r_{i j}=\frac{C_{i j}}{\sqrt{C_{j j} C_{i i}}} ; \quad r=\left(\begin{array}{cc}
1 & -0.9994 \\
-0.9994 & 1
\end{array}\right)
$$

where non-diagonal elements represent the correlation between parameters $c$ and $m$. The closer their values are to 1 (or -1 ), the higher is the correlation. The minus sign means that an increase in the value of one parameter can be compensated by decreasing the other parameter, and vice versa. $C_{i j}$ is the covariance matrix [11]. So, in our case, if we increase $m$ we have to decrease $c$ so that we will get a result (fit) that is not much worse.

Another way to analyze the confidence intervals of the parameters is via the "extra sum-of-squares F test" [12], which is an adaptation of ANOVA (ANalysis of VAriance). It describes the difference between two models (simpler and more complex) using their sum-of-squares of deviations (errors) SS and their corresponding degrees of freedom DF

$$
F=\frac{\left(\mathrm{SS}_{a}-\mathrm{SS}_{b}\right) / \mathrm{SS}_{b}}{\left(\mathrm{DF}_{a}-\mathrm{DF}_{b}\right) / \mathrm{DF}_{b}}
$$

If the relative difference of the sum-of-squares of two different models (in the numerator) is approximately the same as (or smaller than) the relative difference of degrees of freedoms (in the denominator), then the two models are most probably similar and we can use the simpler one. If the relative difference of the sumof-squares is greater than the relative difference in degrees of freedom, then this probability is smaller and the model with the smaller sum-of-squares (the more complex model) is probably better. The probability $\mathcal{P}$ of getting an $F$-ratio less than or equal to a specific value can be described by the $\mathcal{F}$-distribution (FisherSnedecor), see Figure 4. The more frequently used $p$-value, defined as $1-\mathcal{P}$, shows the probability of getting $F$ greater than some specific value. In other words, the $p$-value shows the probability that the simpler model and the more complex model are similar 


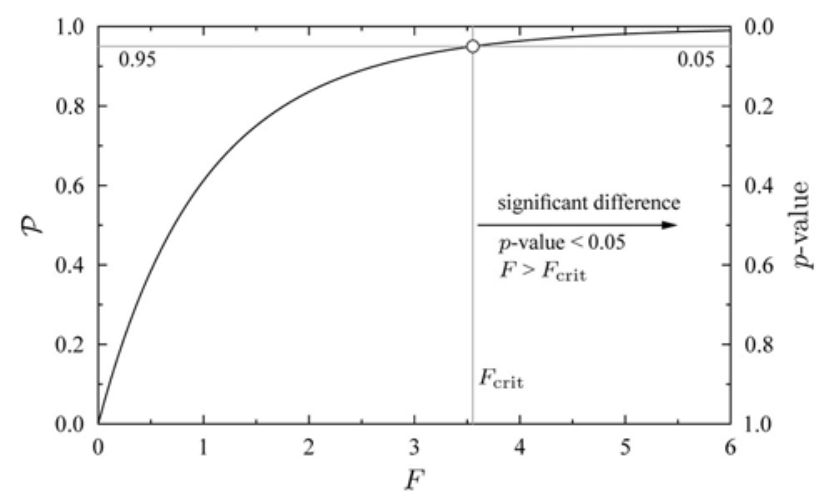

Fig. 4: The $\mathcal{F}$ cumulative distribution function used in the extra sum-of-squares $\mathrm{F}$ test. This describes the probability $\mathcal{P}$ that the $F$-ratio (Eq. 35 ) is less than or equal to some specific value. The more frequently used $p$-value, defined as $1-\mathcal{P}$, shows the probability that the simpler model and the more complicated model are similar (not too different). The lower its value is, the more significant is the difference. If the $p$-value is less than 0.05 , we usually assume the simpler model is not correct and should be rejected

(not too different). If we get a $p$-value less than 0.05 $(5 \%)$, then the two models are considered significantly different and we should reject the simpler model.

Our goal is the reverse. We would like to find a region where the sum-of-squares is not significantly different from the sum-of-squares for our best-fit parameters, so that models with parameters in this region can be considered practically the same (statistically not significantly different). This region can be defined as $[12]$

$$
\mathrm{SS}_{\text {all-fixed }}=\mathrm{SS}_{\text {best-fit }}\left[\frac{p}{n-p} \mathcal{F}_{0.95}(p, n-p)+1\right] \text {, }
$$

where $\mathcal{F}_{0.95}$ represents the inverse cumulative distribution function for the given confidence level of $95 \%, p$ is number of parameters, and $n$ is number of data points. In Matlab, the $\mathcal{F}$ value for $95 \%$ confidence level can be calculated as finv $(0.95, p, n-p)$. Such a confidence region is depicted in Figure 6. The contour command can be used to plot this region in Matlab. Maximum and minimum values of the parameters obtained from this region will give us larger and asymmetric confidence intervals compared to the asymptotic ones, see Eq. (32).

$$
\begin{array}{rlll}
c & =0.276 \ldots & 1.034 \\
m & =0.616 & \ldots & 0.736
\end{array}
$$

Here, we should realize that these two parameters are closely joined together. So if one parameter moves to one side of its confidence interval, the other should also move so that it stays inside the confidence region in Figure 6. This is for example the case of our 1parameter fit (Eq. 33), or the correlation by [2]. Our 1 -parameter fit is very close to the 2 -parameter fit, so it is not plotted in Figure 3. Rieger's correlation is

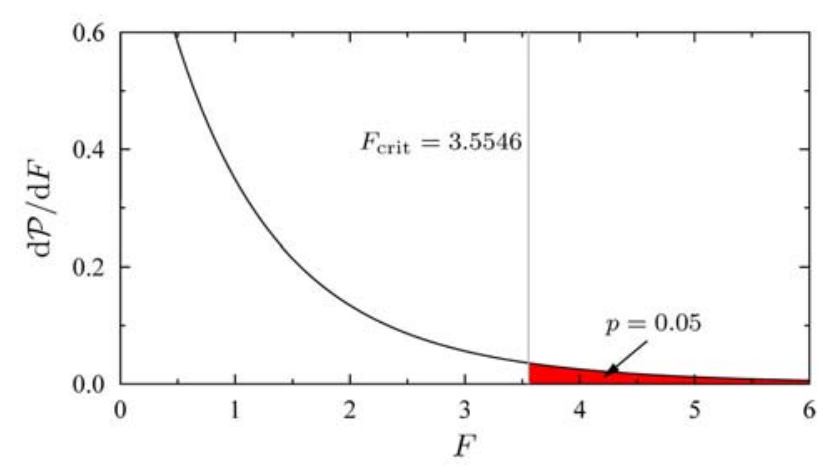

Fig. 5: The probability density function of $\mathcal{F}$-distribution which integrated within a certain range gives the probability of an $F$-ratio located within that range. The filled red area corresponds to $p$-value 0.05 , that is to the probability that the $F$-ratio is greater than the critical value. The critical value $F_{\text {crit }}=3.5546$ stands here for $p$-value 0.05 and degrees of freedom 2 and 18, and can be calculated as finv $(1-0.05,2,18)$ in Matlab

plotted there, and it is close to ours. From the statistical point of view, there is no difference between these models for the $95 \%$ confidence level, so we can be satisfied only with our 1-parametric fit. Let us try to compare situations when we take values of parameters $c$ and $m$ from places near to the left or right margins of our confidence region, denoted in Figure 6 as "test 1" and "test 2 ". They are compared with our 2-parameter fit in Figure 7. The difference is not so big if we look at the data points, and it is not significant from the statistical point of view. Both curves fall into the darker gray region, and this corresponds to the asymptotic confidence band constructed by Matlab command nlpredci with options simopt=on and predopt=curve. This represents an interval where, with $95 \%$ probability, the true best-fit curve should be. The lighter gray and wider band corresponds to the asymptotic prediction band, where $95 \%$ of data points from all following measurements should fall (nlpredci with options simopt=on and predopt=observation).

\section{Conclusions}

We have measured the heat transfer coefficients on tube baffles using the transient method, when the agitated liquid is periodically heated and cooled by the liquid running through tube baffles. For the reported geometrical parameters, the following correlation summarized our data

$$
\mathrm{Nu}=0.54 \operatorname{Re}^{0.675} \operatorname{Pr}^{1 / 3} \mathrm{Vi}^{0.14} .
$$

We have also analyzed the confidence regions of the parameters in the previous correlation, and we found that the one-parameter fit of our data with the commonly used exponent $m=0.67$ 


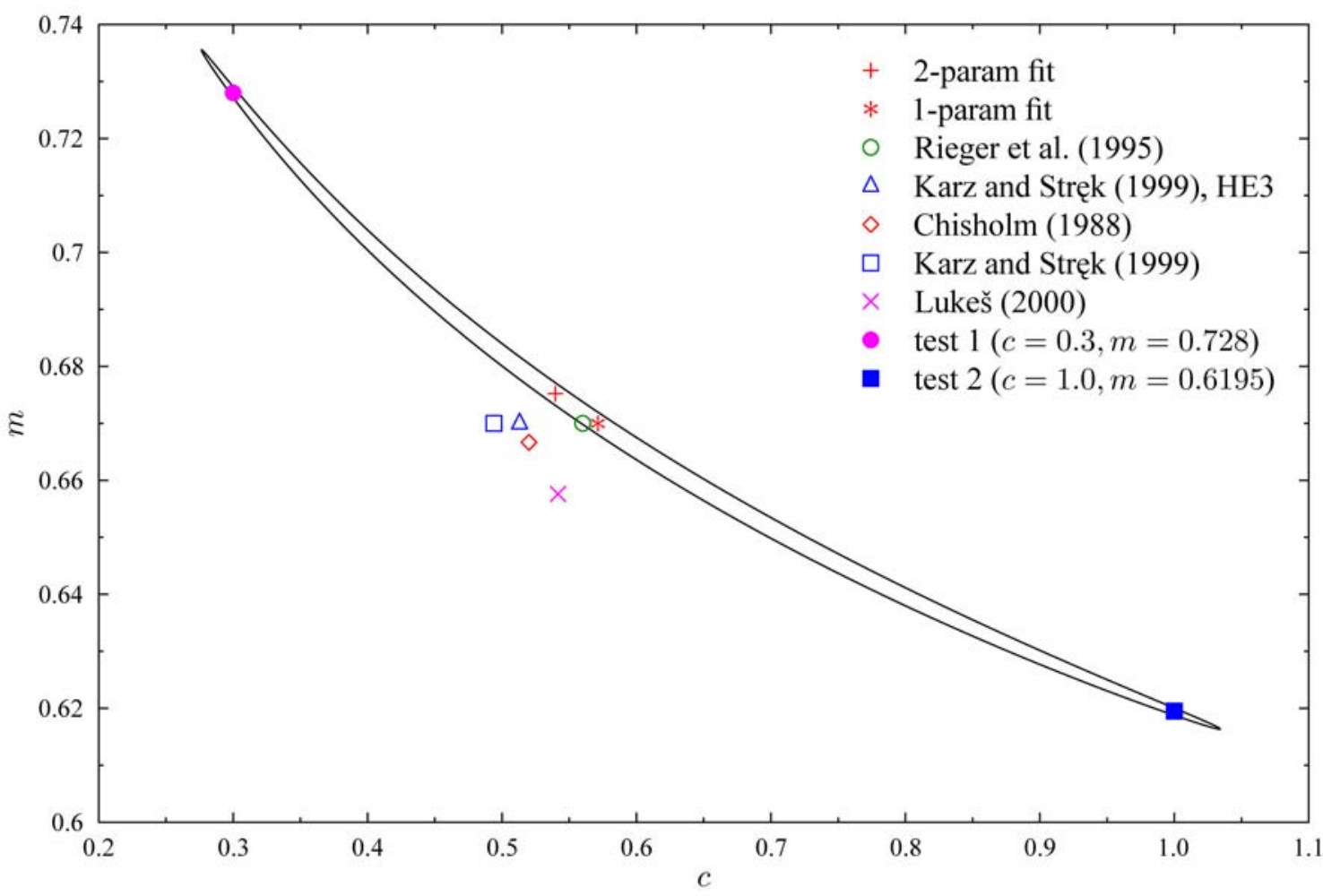

Fig. 6: $95 \%$ confidence region (contour) of parameters $m$ and $c$, which encloses parameter values that produce curves not significantly different from the best-fit curve

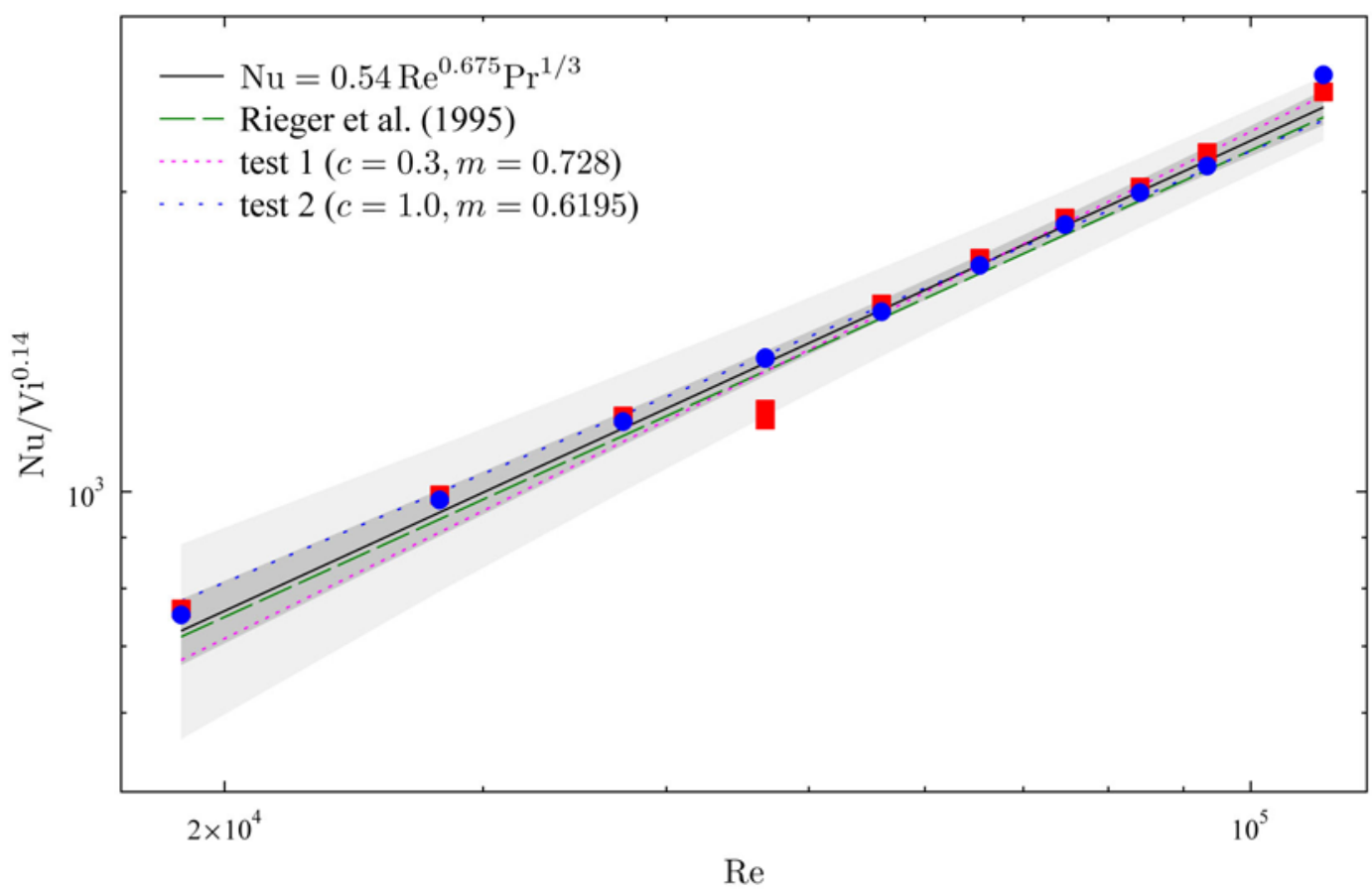

Fig. 7: Comparing two "extreme" values of parameters $c$ and $m$, "test 1" and "test 2", with our best-fit correlation (Eq. 31) and with Rieger et al. [2]. In addition, the darker gray region displayed here corresponds to the asymptotic prediction band where the true best-fit curve should lie with $95 \%$ probability. The lighter gray region is the asymptotic prediction band where $95 \%$ of the data points obtained in many following measurements should fall 
Table 3: Comparison of different impeller types and tube baffle configurations $(4 \times 2$ means four two-tube baffles). Constant $c$, Eq. (6), is given for the commonly used exponent $m=0.67\left(\mathrm{Nu}=c \mathrm{Re}^{0.67} \operatorname{Pr}^{1 / 3} \mathrm{Vi}^{0.14}\right)$. Constant $K$ from the energy characteristic, Eq. (14), is also given for $m=0.67$. The power number $\mathrm{Po}=P / \varrho N^{3} d^{5}$ follows the corresponding references, [5], or our own experiments

\begin{tabular}{llcccc}
\hline authors & $\begin{array}{l}\text { impeller type and tube baffle } \\
\text { configurations }\end{array}$ & $c$ & $K$ & Po & $m$ (two-param. fit) \\
\hline$[3]$ & propeller, $4 \times 4$ & 0.494 & 0.518 & 0.27 & $0.642 \pm 0.075$ \\
& HE3, $4 \times 4$ & 0.513 & 0.406 & 0.95 & $0.665 \pm 0.056$ \\
\hline$[4]$ & pitched six-blade $45^{\circ}, 24 \times 1$ & 0.750 & 0.540 & 1.50 & - \\
& propeller, $24 \times 1$ & 0.640 & 0.630 & 0.37 & - \\
\hline$[5]$ & pitched three-blade $45^{\circ}, 4 \times 2$ & 0.494 & 0.393 & 0.93 & 0.6576 \\
\hline \hline this work & pitched six-blade $45^{\circ}, 4 \times 2$ & 0.571 & 0.396 & 1.60 & $0.676 \pm 0.047$ \\
\hline
\end{tabular}

$$
\mathrm{Nu}=0.571 \operatorname{Re}^{0.67} \operatorname{Pr}^{1 / 3} \mathrm{Vi}^{0.14}
$$

and the correlation in [2] also fall into the $95 \%$ confidence region, producing curves which are not significantly different from the best-fit curve (from the statistical point of view). Table 3 summarizes the constants of the heat, energy and power characteristics for corresponding correlations.

\section{Acknowledgement}

This work has been supported by research project of the Czech Ministry of Education MSM6840770035.

\section{References}

[1] Chisholm, D., ed.: Heat Exchanger Technology, Elsevier Applied Science (1988).

[2] Rieger, F., Novák, V., Ditl, P., Fořt, I., Vlček, J., Ludvík, M., Machoň, V., Medek, J.: Míchání a míchací zařízení, MAPRINT 9, ČSChI, Praha (1995), in Czech.

[3] Karcz, J., Stręk, F.: Heat Transfer in Agitated Vessel Equipped with Tubular Coil and Axial Impeller, MIESZANIE '99 (1999), pp. 135-140.

[4] Karcz, J., Stręk, F., Major, M., Michalska, M.: Badania efektywności wnikania ciepła w mieszalniku z pionową wężovnicą rurową, Inżynieria $i$ aparatura chemiczna (2002), pp. 76-78.

[5] Lukeš, J.: Mixing Equipment with Tube Baffles, Master Thesis, Czech Technical University in Prague (2000), in Czech.

[6] Petera, K., Dostál, M., Rieger, F.: Transient Measurement of Heat Transfer Coefficient in Agitated Vessel, in Mechanical Engineering 2008, Slovak University of Technology, Bratislava (2008).
[7] Shah, R. K., Sekulić, D. P.: Fundamentals of Heat Exchanger Design, JohnWiley \& Sons (2003).

[8] Schlünder, E. U., ed.: VDI-Wärmeatlas (Berechnungsblätter für den Wärmeübergang), VDI Verlag, Düsseldorf (1994).

[9] Acheson, D.: From Calculus to Chaos: An Introduction to Dynamics, Oxford University Press (1997).

[10] Dostál, M., Petera, K., Rieger, F.: Measurement of Heat Transfer Coefficients in Agitated Vessel with Tube Baffles, in CHISA Conference, Srní (2009), in Czech.

[11] Press, W. H., Teukolsky, S. A., Vetterling, W. T., Flannery, B. P.: Numerical Recipes: The Art of Scientific Computing, Cambridge University Press (1992), 2nd Edition.

[12] Motulsky, H. J., Christopulos, A.: Fitting Models to Biological Data Using Linear and Nonlinear Regression. A Practical Guide to Curve Fitting, GraphPad Software Inc., San Diego CA, http://www.graphpad.com (2003).

Ing. Martin Dostál, Ph.D.

Phone: +420224358489

E-mail: martin.dostal@fs.cvut.cz

Department of Process Engineering

Faculty of Mechanical Engineering

Czech Technical University in Prague

Technická 4, 16607 Prague 6, Czech Republic

Ing. Karel Petera, Ph.D.

Phone: +420224359 949

E-mail: karel.petera@fs.cvut.cz

Department of Process Engineering

Faculty of Mechanical Engineering

Czech Technical University in Prague

Technická 4, 16607 Prague 6, Czech Republic 
Prof. Ing. František Rieger, DrSc.

Phone: +420224352548

E-mail: frantisek.rieger@fs.cvut.cz

Department of Process Engineering

Faculty of Mechanical Engineering

Czech Technical University in Prague

Technická 4, 16607 Prague 6, Czech Republic

\section{Nomenclature}

$a$

$c$

$c_{\mathrm{PB}}$

$c_{\mathrm{P}}$

$C_{i j}$

$d$

$d_{\mathrm{Bi}}$

$d_{\mathrm{Be}}$

$D$

$D_{\mathrm{B}}$

$\mathrm{DF}$

F

$\mathcal{F}$

$\mathrm{H}_{2}$

H

$k$

$k_{1,2}$

K

$m$

$\dot{m}_{\mathrm{B}}$

M

$n$

$n$

$N$

$\mathrm{Nu}$

$\mathrm{Nu}_{\mathrm{B}}$

$p$

$p$

$P$

$\mathcal{P}$

Po

Pr

$\operatorname{Pr}_{\mathrm{B}}$

$q$

$\dot{Q}$

$r_{i j}$

Re

$\mathrm{Re}_{\mathrm{B}}$

$\mathrm{Re}^{*}$

$s$

$S$

SS

$t$

$T$

$T_{0}$

$T_{\mathrm{B}}$

$T_{\mathrm{B}}^{\prime}$

$T_{\mathrm{B}}^{\prime \prime}$

thermal diffusivity $\left(\mathrm{m}^{2} \mathrm{~s}^{-1}\right)$

model parameter $(-)$

specific heat capacity of heating or cooling liquid B $\left(\mathrm{J} \mathrm{kg}^{-1} \mathrm{~K}^{-1}\right)$

specific heat capacity of an agitated liquid $\left(\mathrm{J} \mathrm{kg}^{-1} \mathrm{~K}^{-1}\right)$

covariance matrix, $[11] \quad(-)$

impeller diameter $(\mathrm{m})$

inner diameter of tube baffle (m)

outer diameter of tube baffle $(\mathrm{m})$

inner diameter of vessel $(\mathrm{m})$

tube baffle diameter $(\mathrm{m})$

degrees of freedom (-)

ratio of the sum-of-squares and degrees of freedom for two different models (-)

cumulative F-distribution function (Fisher-Snedecor distribution) (-)

clearance between impeller and vessel bottom (m)

height of agitated liquid in the vessel $(\mathrm{m})$

overall heat transfer coefficient $\left(\mathrm{W} \mathrm{m}^{-2} \mathrm{~K}^{-1}\right)$

Euler's method constants $\left({ }^{\circ} \mathrm{C}, \mathrm{K}\right)$

model parameter $(-)$

model parameter $(-)$

mass flowrate of heating (cooling) liquid B $\quad\left(\mathrm{kg} \mathrm{s}^{-1}\right)$

mass of agitated liquid $(\mathrm{kg})$

model parameter $\quad(-)$

number of measurements $(-)$

impeller rotation speed $\left(\mathrm{s}^{-1}\right)$

Nusselt number $\quad(-)$

Nusselt number of heating (cooling) liquid B (-)

number of parameters $(-)$

$p$-value, probability $1-\mathcal{P} \quad(-)$

power input (W)

probability $(-)$

power number $(-)$

Prandtl number $\quad(-)$

Prandtl number for heating (cooling) liquid B (-)

heat flux $\left(\mathrm{W} \mathrm{m}^{-2}\right)$

heat transfer rate $(\mathrm{W})$

correlation matrix, coefficient $\quad(-)$

Reynolds number (-)

Reynolds number for heating (cooling) liquid B (-)

modified Reynolds number (-)

model parameter $\quad(-)$

heat transfer area $\left(\mathrm{m}^{2}\right)$

sum of squares, Eq. (30) (-)

time $(\mathrm{s})$

temperature, temperature of agitated liquid $\quad\left({ }^{\circ} \mathrm{C}, \mathrm{K}\right)$

initial temperature of agitated liquid $\left({ }^{\circ} \mathrm{C}, \mathrm{K}\right)$

temperature of heating (cooling) liquid $\mathrm{B} \quad\left({ }^{\circ} \mathrm{C}, \mathrm{K}\right)$

inlet temperature of heating (cooling) liquid $\mathrm{B} \quad\left({ }^{\circ} \mathrm{C}, \mathrm{K}\right)$

outlet temperature of heating (cooling) liquid $\mathrm{B} \quad\left({ }^{\circ} \mathrm{C}, \mathrm{K}\right)$ 


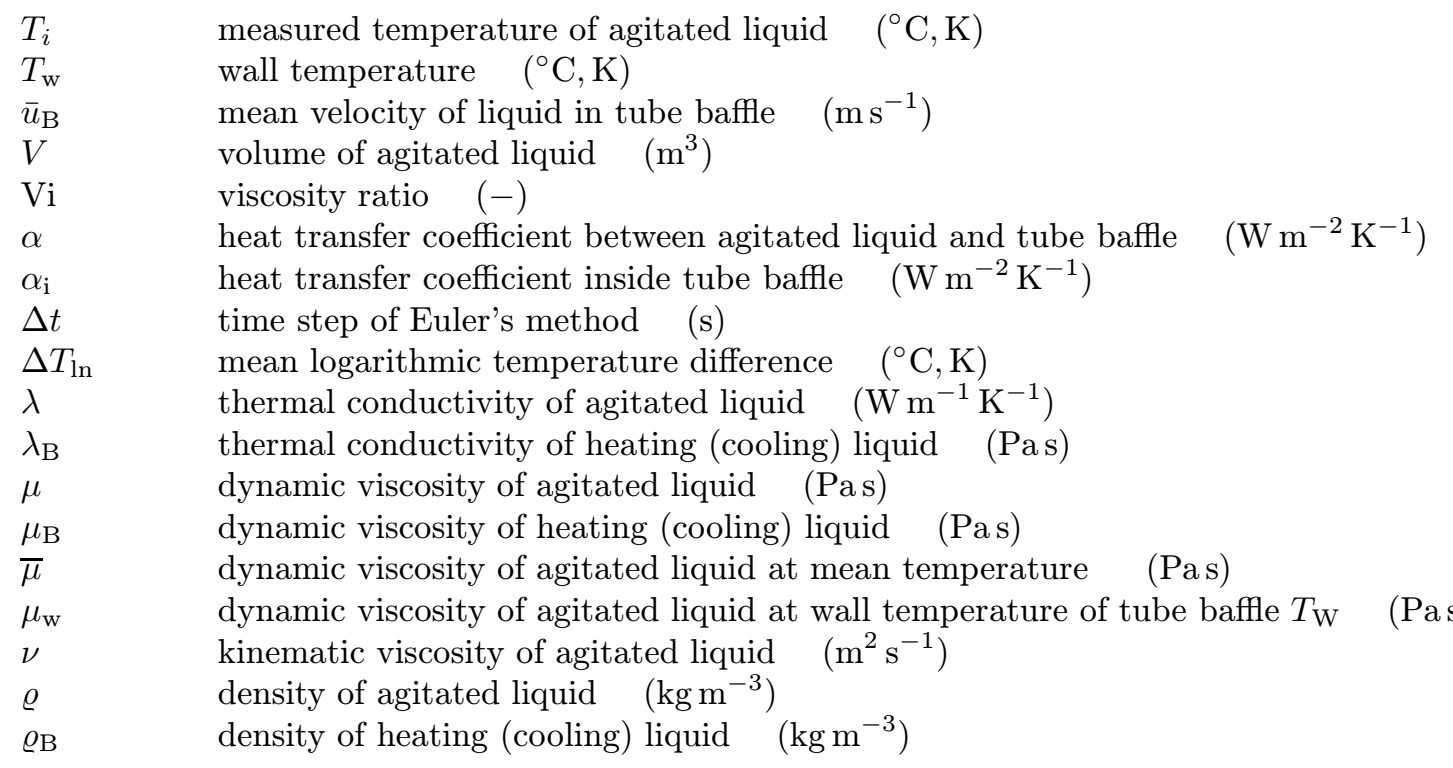

